\title{
The Role of Values in Coping with Health and Economic Threats of COVID-19
}

Edward P. Lemay, Jr.

Arie W. Kruglanski

Erica Molinario

Maximilian Agostini

Jocelyn J. Bélanger

Ben Gützkow

Jannis Kreienkamp

Michelle R. vanDellen

PsyCorona Collaboration

N. Pontus Leander
University of Maryland, College Park

University of Maryland, College Park

Florida Gulf Coast University

University of Groningen

New York University Abu Dhabi

University of Groningen

University of Groningen

University of Georgia

University of Groningen

\section{Author Note}

This research received support from the New York University Abu Dhabi (VCDSF/7571015), the University of Groningen (Sustainable Society \& Ubbo Emmius Fund), the Instituto de Salud Carlos III (COV20/00086), and co-funded by the European Regional Development Fund (ERDF), "A way to make Europe." Correspondence concerning this article should be addressed to Edward Lemay, Department of Psychology, University of Maryland, College Park, MD, 20742. Email: elemay@umd.edu. This study complies with ethical regulations for research on human subjects, as approved by the Ethics Committee of Psychology at the University of Groningen (protocol PSY-1920-S-0390) and the Institutional Review Board at New York University Abu Dhabi (protocol HRPP-2020-42).

The PsyCorona Collaboration consists of these additional authors: Georgios

Abakoumkin, University of Thessaly; Jamilah Hanum Abdul Khaiyom, International Islamic University Malaysia; Vjollca Ahmedi, Pristine University; Handan Akkas, Ankara Science University; Carlos A. Almenara, Universidad Peruana de Ciencias Aplicadas; Mohsin Atta, University of Sargodha; Sabahat Cigdem Bagci, Sabanci University; Sima Basel, New York 
University Abu Dhabi; Edona Berisha Kida, Pristine University; Nicholas R. Buttrick, University of Virginia; Phatthanakit Chobthamkit, Thammasat University; Hoon-Seok Choi, Sungkyunkwan University; Mioara Cristea, Heriot Watt University; Sára Csaba, ELTE Eötvös Loránd University, Budapest; Kaja Damnjanovic, University of Belgrade; Ivan Danyliuk, Taras Shevchenko National University of Kyiv; Arobindu Dash, Leuphana University of Luneburg; Daniela Di Santo, University "La Sapienza", Rome; Karen M. Douglas, University of Kent; Violeta Enea, Alexandru Ioan Cuza University, Iasi; Daiane Gracieli Faller, New York University Abu Dhabi; Gavan Fitzsimons, Duke University; Michele J. Gelfand, University of Maryland; Alexandra Gheorghiu, Alexandru Ioan Cuza University; Ángel Gómez, Universidad Nacional de Educación a Distancia; Ali Hamaidia, Setif 2 University; Qing Han, University of Bristol; Mai Helmy, Menoufia University; Joevarian Hudiyana, Universitas Indonesia; Bertus F. Jeronimus, University of Groningen; Ding-Yu Jiang, National Chung-Cheng University; Veljko Jovanović, University of Novi Sad; Željka Kamenov, University of Zagreb; Anna Kende, ELTE Eötvös Loránd University, Budapest; Shian-Ling Keng, Yale-NUS College; Tra Thi Thanh Kieu, HCMC University of Education; Yasin Koc, University of Groningen; Kamila Kovyazina, Independent researcher, Kazakhstan; Inna Kozytska, Taras Shevchenko National University of Kyiv; Joshua Krause, University of Groningen; Anton Kurapov, Taras Shevchenko National University of Kyiv; Maja Kutlaca, Durham University; Nóra Anna Lantos, ELTE Eötvös Loránd University, Budapest; Cokorda Bagus Jaya Lesmana, Udayana University; Winnifred R. Louis, University of Queensland; Adrian Lueders, Université Clermont-Auvergne; Najma Iqbal Malik, University of Sargodha; Anton Martinez, University of Sheffield; Kira O. McCabe, Vanderbilt University; Jasmina Mehulić, University of Zagreb; Mirra Noor Milla, Universitas Indonesia; Idris Mohammed, Usmanu Danfodiyo University 
Sokoto; Manuel Moyano, University of Cordoba; Hayat Muhammad, University of Peshawar; Silvana Mula, University "La Sapienza", Rome; Hamdi Muluk, Universitas Indonesia; Solomiia Myroniuk, University of Groningen; Reza Najafi, Islamic Azad University, Rasht Branch; Claudia F. Nisa, New York University Abu Dhabi; Boglárka Nyúl, ELTE Eötvös Loránd University, Budapest; Paul A. O’Keefe, Yale-NUS College; Jose Javier Olivas Osuna, National Distance Education University (UNED); Evgeny N. Osin, National Research University Higher School of Economics; Joonha Park, NUCB Business School; Gennaro Pica, University of Camerino; Antonio Pierro, University "La Sapienza", Rome; Jonas Rees, University of Bielefeld; Anne Margit Reitsema, University of Groningen; Elena Resta, University "La Sapienza", Rome; Marika Rullo, University of Siena; Michelle K. Ryan, University of Exeter, University of Groningen; Adil Samekin, International Islamic Academy of Uzbekistan; Pekka Santtila, New York University Shanghai; Edyta Sasin, New York University Abu Dhabi; Birga M. Schumpe, New York University Abu Dhabi; Heyla A. Selim, King Saud University, Saudi Arabia, Riyadh; Michael Vicente Stanton, California State University, East Bay; Wolfgang Stroebe, University of Groningen; Samiah Sultana, University of Groningen; Robbie M. Sutton, University of Kent; Eleftheria Tseliou, University of Thessaly; Akira Utsugi, Nagoya University; Jolien Anne van Breen, Leiden University; Caspar J. Van Lissa, Utrecht University; Kees Van Veen, University of Groningen; Alexandra Vázquez, Universidad Nacional de Educación a Distancia; Robin Wollast, Université Clermont-Auvergne; Victoria Wai-lan Yeung, Lingnan University; Somayeh Zand, Islamic Azad University, Rasht Branch; Iris Lav Žeželj, University of Belgrade; Bang Zheng, Imperial College London; Andreas Zick, University of Bielefeld; Claudia Zúñiga, Universidad de Chile. 
Correspondence concerning this article should be sent to Edward Lemay, Department of Psychology, University of Maryland, College Park, Maryland, 20742. Email: elemay@umd.edu. 


\begin{abstract}
The current research examined the role of values in guiding people's responses to COVID-19. Results from an international study involving 115 countries $(N=61,490)$ suggest that health and economic threats of COVID-19 evoke different values, with implications for controlling and coping with the pandemic. Specifically, health threats evoked prioritization of communal values related to caring for others and belonging, whereas economic threats predicted prioritization of agentic values focused on competition and achievement. Concurrently and over time, prioritizing communal values over agentic values was associated with enactment of prevention behaviors that reduce virus transmission, motivations to help others suffering from the pandemic, and positive attitudes toward outgroup members. These results, which were generally consistent across individual and national levels of analysis, suggest that COVID-19 threats may indirectly shape important responses to the pandemic through their influence on people's prioritization of communion and agency. Theoretical and practical implications are discussed.

Keywords: values, disease, COVID-19, prosocial behavior, prejudice
\end{abstract}




\section{The Role of Values in Coping with Health and Economic Threats of COVID-19}

The 2019 coronavirus disease (COVID-19) has had widespread impacts. Millions of cases have been reported across the globe, resulting in hundreds of thousands of deaths (World Health Organization, 2021). The disease has caused volatility in financial markets, reductions in demand for products, and mass unemployment all over the world (Barua, 2020; Goodell, 2020; Nicola et al., 2020). In the current research, we examine psychological and behavioral responses to these threats, with a focus on the intermediary role of values. Values describe what is important or desirable to people, and they shape motivation, cognition, and behavior across a variety of situations (Rokeach, 1973; Schwartz, 2015). Values also change in response to opportunities, challenges, and life-altering events (Bardi et al., 2009; Schwartz, 2015), and these changes help peple navigate their social and natural environments (Fischer \& Boer, 2016). Affirmation of one's values can also help people cope with feelings of vulnerability or other psychological threats (Sherman \& Cohen, 2006). Hence, the specific threats people experience as a result of disease outbreaks such as COVID-19 may influence the values they prioritize, which may guide other responses to these outbreaks.

Values can be organized according to their relevance to communion and agency (Locke, 2000; Trapnell \& Paulhus, 2012). Communal values involve a concern for others' welfare and the maintenance of harmonious relations with others, whereas agentic values involve a selfinterested focus on enhancing one's standing within social hierarchies, such as striving for achievement and status. This distinction between concern for others and relationships on the one hand, versus a focus for personal advancement on the other, forms a fundamental dimension along which many more specific human values are distinguished (Fischer \& Boer, 2016; Schwartz, 2015). The prioritization of these values is thought to be important for people's 
psychological functioning and behavior, and is thought to vary across people and cultures (Locke, 2000; Schwartz, 2015; Trapnell \& Paulhus, 2012). These values may be shaped by disease threats, including those associated with COVID-19. In the current research, we examine whether the prioritization of communal versus agentic values mediate the effects of COVID-19 infection and economic threats on important responses to the pandemic.

People vary in their concerns about infection, and recurrent concerns elicit psychological and behavioral responses to mitigate the likelihood and impact of infection (Ackerman, Hill, \& Murray, 2018; Murray \& Schaller, 2016; Thornhill \& Fincher, 2014). The threat of becoming infected may engender a sense of vulnerability or weakness, and heighten people's felt dependency on others for safety and support. Affiliation offers protection against threats to safety and necessary aid during times of illness (Baumeister \& Leary, 1995; Thornhill \& Fincher, 2014). Hence, physical threats and fear motivate people to seek interpersonal closeness (Mikulincer \& Shaver, 2009; Schachter, 1959; Strumpfer, 1970). Reminders about death have similar effects, increasing motivation to maintain close relationships (Mikulincer \& Shaver, 2009). According to Thornhill and Fincher's (2014) parasite stress theory, collectivistic values emphasizing the importance of interpersonal and in-group ties provide protection against contracting potentially lethal diseases, and so people living in regions characterized by high pathogen prevalence endorse these collectivistic values (see also Chiao \& Blizinsky, 2009). Similarly, at the individual level, perceived vulnerability to disease is associated with greater conformity, an indicator of collectivistic values (Wu \& Chang, 2012). The threat of contagion may also reduce the appeal of exploring the environment and pursuing new opportunities, as these activities may expose people to pathogens (Thornhill \& Fincher, 2014). Hence, during a 
disease outbreak, including the COVID-19 pandemic, the threat of personal contagion may be associated with a prioritization of communal values over agentic values.

Although it seems feasible that economic threats associated with disease outbreaks also evoke communal values, given that people might turn to others for resources, prior research suggests otherwise. Financial strain is associated with lower quality of interpersonal relationships (Conger et al., 1999; Vinokur et al., 1996; Williamson et al., 2013; Sturgeon et al., 2014), and lower commitment to maintaining relationships (Barton et al., 2015). Merely reminding people of the concept of money reduces their helpfulness and desires for intimacy, and increases their preference for solitary activities (Lodder et al., 2019; Vohs, 2015). These findings suggest that economic threats interfere with the motivation and ability to maintain relationships. People may respond to economic threats associated with disease by attempting to restore economic security, and may prioritize agentic values focused on competition and achievement, presuming they are more useful for restoring economic security relative to communion. Further, attempting to restore economic security through agency may divert resources away from pursuing communion (Hagemeyer et al., 2015; Kumashiro et al., 2008). Hence, COVID-19 economic threats may encourage prioritization of agentic values over communal values.

\section{Implications for Responses to COVID-19}

Given the importance of values for motivation, cognition, and behavior (Rokeach, 1973; Schwartz, 2015), people's prioritization of communal or agentic values in response to disease threats may shape other responses to disease outbreaks. If the relative prioritization of agency versus communion is fundamental for people's psychological functioning, it should influence a variety of responses rather than be limited to any single response. Three independent and 
important responses to COVID-19 are considered in the current research: prevention behavior, prosocial motivation, and prejudice during COVID-19.

\section{Prevention Behavior}

In March 2020, three infection prevention behaviors were recommended by the World Health Organization (2020) to reduce the spread of COVID-19: hand washing, avoiding crowds, and self-isolating, and behaviors involving physical distancing have been shown to reduce transmission of the coronavirus (Islam et al., 2020; Prem et al., 2020). Values may determine people's motivation to enact these behaviors. People who value communion tend to care about others' welfare (Sagiv et al., 2017; Trapnell \& Paulhus, 2012), whereas people who focus on agentic values are less motivated to help others (Daniel et al., 2014). Hence, people who prioritize communal values over agentic values may be particularly likely to enact behaviors that prevent transmission and protect other people and society at large.

Given that people who value communion tend to seek interpersonal closeness (Trapnell \& Paulhus, 2012), an alternative prediction is that these individuals will seek physical proximity to others and have difficulty complying with social distancing measures. However, people who value communion may engage in a process of substitution, in which they select an alternative means to pursue their affiliation goals (Baumeister \& Leary, 1995; Kruglanski et al., 2002). Specifically, given that in-person contact may be viewed as a problemmatic means for affiliation due to its potential to cause harm to oneself and others, those who prioritize communion in response to COVID-19 threats may pursue online contact as a substitute means to maintain interpersonal closeness. Indeed, prior research suggests that online contact with social network members (e.g., posting on social media and video calls) can satisfy people's desires for social connection (Deters \& Mehl, 2013; Teater et al., 2021; Tsai et al., 2010). 


\section{Prosocial Motivation}

COVID-19 is having a profound impact on mental health (Holmes et al., 2020). Coping with large-scale disasters depends, in part, on the receipt of social support (Kaniasty \& Norris, 1993; McGuire et al., 2018). With regard to COVID-19 specifically, perceived social support was associated with fewer depression symptoms and better sleep quality for people undergoing social isolation and physical distancing (Grey et al., 2020). Hence, people's willingness to help others may attenuate the mental and physical health burden of the COVID-19 pandemic. Helping others may also reduce the physical health and economic burdens of COVID-19 through other routes, such as when people run personal errands for vulnerable individuals so they can minimize the likelihood of infection, or when they donate to relief organizations to address economic hardships. Given that communal values involve valuing others' welfare (Sagiv et al., 2017; Trapnell \& Paulus, 2012), people who prioritize communion in response to COVID-19 threats should be particularly motivated to help those suffering from the pandemic.

\section{Prejudice}

Disease and economic threats are often associated with higher levels of ethnocentrism and prejudice (Butz \& Yogeeswaran, 2011; Schaller \& Neuberg, 2012), and this includes threats associated with COVID-19 (Hartman et al., 2021; Roberto et al., 2020). Disease threats may be especially associated with prejudice toward immigrants, who may be viewed as outsiders who bring contagious diseases and consume scarce resources (Schaller \& Neuberg, 2012; Stephan et al., 1999). However, this may depend on the values elicited by disease threats. Threats that activate communal values may be associated with reduced prejudice toward immigrants. Those who value communion exhibit a universal care for the welfare of others, even those beyond their ingroup, and have exhibited lower prejudice in prior research not focused on responses to disease 
(Rokeach, 1973; Schwartz, 2015; Trapnell \& Paulhus, 2012). In contrast, those who emphasize agency report greater prejudice toward immigrants (Leong \& Ward, 2006; Saroglou, Lamkaddem, Van Pachterbeke, \& Buxant, 2009; Shin \& Dovidio, 2018). Hence, the impact of COVID-19 on prejudice may depend on the values evoked by the health and economic threats people experience during the pandemic.

\section{Societal Phenomena}

In addition to individual-level phenomena, the processes described above may operate at the level of nations. The health and economic consequences of COVID-19 vary across nations (Barua, 2020; Dowd et al., 2020; Dryhurst et al., 2020; World Health Organization, 2020). Societal-level variation in COVID-19 threats may, in turn, produce societal-level changes in values (Bardi \& Goodwin, 2011; Rokeach, 1973), and, indeed, values exhibit systematic variation across cultures (Schwartz \& Sagiv, 1995). National differences in experiencing the pandemic primarily as a threat to health versus financial well-being may predict differences in cultural values through the processes described earlier - denizens may prioritize communion due to a need for support and protection from health threats, or prioritize agency to restore economic security. Consistent with this possibility, collectivism and conformity, cultural values that suggest prioritization of communion over agency, are higher in regions characterized by greater pathogen prevalence (Fincher et al., 2008; Murray et al., 2011). In turn, national differences in values may explain national variation in infection prevention behaviors, motivation to help those suffering from the pandemic, and attitudes toward immigrants. Nations that primarily experience COVID-19 as a threat to health may exhibit greater infection prevention behaviors, more prosocial behavior toward citizens suffering from the pandemic, and positive attitudes toward immigrants, in part, because these nations prioritize communion over agency. Societies that 
instead experience COVID-19 as mainly an economic threat may exhibit reduced infection prevention behaviors, lower motivation to help those suffering from the pandemic, and greater prejudice toward immigrants, in part, because these societies value agency over communion.

\section{Current Research}

The current research examined implications of COVID-19 health and economic threat perceptions for the prioritization of communal and agentic values. In addition, we examine the implications of these values for prevention behaviors, social contact, prosocial motivation, and attitudes toward immigrants, at both individual and cultural levels. Health and economic threats may indirectly shape these responses because they evoke different values. Hence, indirect effects of threats on these outcomes via values were examined.

Support for these indirect effects would make novel contributions to understanding the sources of individual and cultural variation in values, as well as people's responses to pathogens generally and COVID-19 in particular. Most relevant to the current research, models of individual-variation in values have emphasized the role of adaptation to life changes as a source of change in people's values (Bardi \& Goodwin, 2011; Fischer \& Boer, 2016). Likewise, models of cultural variation in values suggest that cultural variation in pathogen prevalence predicts cultural variation in collectivism, which facilitates adaptation to environmental pathogens (Chiao \& Blizinsky, 2009; Fischer \& Boer, 2016; Thornhill \& Fincher, 2014). The current research suggests that, at both individual and cultural levels, interpretation of diseases as threatening physical versus economic welfare may shape the direction of value adaptation. Furthermore, support for the indirect pathways described above would suggests that this adaptation of values has implications for myriad responses to disease outbreaks of social and epidemiological significance. This research also contributes to understanding psychological and behavioral 
responses to the health and economic threats imposed by COVID-19 specifically, which, to our knowledge, has not documented a mediating role of communal and agentic values.

Prior research on personal values suggests that values are ordered hierarchically by their importance, and that the trade-off among values, rather than absolute importance, guides action (Rokeach, 1973; Rokeach \& Ball-Rokeach, 1989; Sagiv et al., 2017; Schwartz, 2007; 2015). Accordingly, we examined the relative prioritization of communion and agency. Measures of relative value priorities correct for response biases and allow researchers to identify the priorities among values that guide behavior even when multiple values are important in an absolute sense (Rokeach, 1973; Rokeach \& Ball-Rokeach, 1989; Schwartz, 2007; 2015). The current research was an international study across 115 nations. Concurrent associations were examined using data reported by over 60,000 people. Prospective models examined changes over time using longitudinal data reported by a subset of participants.

\section{Method}

\section{Participants and Procedure}

Data were from PsyCorona, a longitudinal study on COVID-19 (www.psycorona.org). Participants were recruited using convenience sampling, snowball sampling, and paid procedures. The baseline sample consisted of 61,490 participants across the globe who completed an online questionnaire between March 19th and July $6^{\text {th }}, 2020$, in one out of 30 possible languages. ${ }^{1}$ The initial survey served as a platform to recruit for the longitudinal component via a separate invitation from within the survey. Those who agreed to receive invitations for the follow-up surveys provided their contact information. Given the rapidly developing pandemic, distribution of the weekly follow-up surveys began the week after launching the baseline survey (March $27^{\text {th }}$ ); subsequent follow-up surveys were administered on 
a rolling basis, which continued approximately every week thereafter for 7 follow-up

assessments. Altogether, sample sizes for the longitudinal assessments varied by both the timing of participants' initial survey response and participants' continued willingness to volunteer. The baseline sample included $61.5 \%$ women and 37.9\% men (561 did not report gender or reported a gender of "other"). Age was assessed in eight intervals: aged 18 to 24 (23.1\%), 25-34 (24.5\%), 35-44 (19.1\%), $45-54$ (14.2\%), 55-64 (11.2\%), 65-75 (6.9\%), 76-85 (0.9\%), and older than 85 (0.1\%) (283 did not report age).

This study complies with ethical regulations for research on human subjects, as approved by the Ethics Committee of Psychology at Groningen University and the Institutional Review Board at New York University Abu Dhabi. Data and a copy of the measures are available on the Open Science Framework (https://osf.io/5aw6f).

\section{Measures}

Participants completed the measures described below in addition to measures unrelated to this investigation. All of the measures described below were completed during the baseline assessment. Some of them were completed again during follow-up assessments. Inclusion of some measures varied across the follow-up administrations, which explains the variation in timing described below (i.e., why the primary follow-up measures were administered in the third through sixth follow-up assessments).

\section{COVID-19 Infection Threat}

Participants indicated the subjective likelihood of getting infected with the coronavirus in the next few months using an 8-point scale (1 = "Exceptionally unlikely"; 7 = "All but certain"; $8=$ "Already happened"), which was based on research on perceived threats (Leander et al., 2019; Smith et al., 2012). In addition, they rated how disturbing it would be to contract the virus 
using a 5-point scale (1 = "Not disturbing at all"; 5 = "Extremely disturbing"). Responses to these two items were only weakly positively correlated $(r=.10, p<.001)$, suggesting they capture unique aspects of infection threat. Responses were standardized and averaged to assess COVID-19 infection threat. Higher values reflect greater perceived threat of infection.

\section{COVID-19 Economic Threat}

Participants rated the likelihood of experiencing negative economic consequences of coronavirus using an 8-point scale (1 = "Exceptionally unlikely"; 7 = "All but certain"; $8=$ “Already happened”). They also completed a 4-item measure assessing job insecurity (Vander Elst, et al., 2014) (“Chances are, I will soon lose my job”; "I am sure I can keep my job”; "I feel insecure about the future of my job"; "I already lost my job") using a 5-point scale (-2 = "Strongly disagree"; $2=$ "Strongly agree") $(\alpha=.82)$. The item worded in the positive direction was reverse-scored, and those who indicated that these questions were not applicable to them (e.g., students, retired people) did not provide data. Participants also completed a 3-item measure of financial strain (Selenko \& Batinic, 2011) ("I am financially strained”; "I often think about my current financial situation"; "Due to my financial situation, I have difficulties paying for my expenses") using the same 5-point scale $(\alpha=.85)$. They also rated how disturbing it would be to suffer negative economic consequences of the coronavirus using a 5-point scale $(1=$ "Not disturbing at all"; 5 = "Extremely disturbing"). Responses to these four measures were standardized and averaged to create an index of COVID-19 economic threat. Higher values indicate greater perceived threat to economic welfare $(\alpha=.71)$.

\section{Personal Values}

Participants ranked six qualities (achievement, creativity, innovation, sacrifice, cooperation, altruism) in terms of the value they accorded to each ( 1 = "I value this the most"; 6 
$=$ "I value this the least"). Ranks were reverse-scored so that higher values suggest greater importance. Ranks ascribed to cooperation, sacrifice, and altruism were averaged. Higher values indicate prioritization of communion, and lower values indicate prioritization of agency. This measure was based on prior research examining relative value priorities (Kahle et al., 1986; Rokeach, 1973; Schwartz, 2007; 2015; Trapnell \& Paulhus, 2012). To examine change over time in values, the primary longitudinal analyses used responses to these items provided by a subset of participants during the sixth follow-up assessment ( $n=6,514$; completed, on average, 32 days after completion of the baseline assessment).

\section{Infection Prevention Behaviors}

In March 2020, three infection prevention behaviors were recommended by the World Health Organization (2020): hand washing, avoiding crowds, and self-isolating. Participants read, "to minimize my chances of suffering from coronavirus, I...," follow by three behaviors: "wash my hands more often"; "avoid crowded spaces"; "put myself in quarantine." The three items were completed using 7-point response scales (-3: "strongly disagree"; 3: "strongly agree") $(\alpha=.74)$. To examine change over time, the primary longitudinal analyses used responses provided by a subset of participants during the fourth follow-up $(n=8,029$; completed, on average, 20 days after baseline).

\section{In-person and Online Social Contact}

Participants indicated how often in the last seven days they had social contact with friends or relatives, both for in-person contact and online (video or voice) contact. Participants provided separate estimates of the number of days on which they had each type of contact (0-7).

\section{Prosocial Motivation}


Participants indicated their agreement with four statements regarding their willingness to help others ("help others who suffer from coronavirus"; "make donations to help others that suffer from coronavirus"; "protect vulnerable groups from coronavirus even at my own expense"; "make personal sacrifices to prevent the spread of coronavirus") using 7-point scales (-3: "strongly disagree"; 3: "strongly agree") $(\alpha=.77)$. This measure was adapted from research on prosocial behavior (Van Zomeren et al., 2008). The primary longitudinal analyses used responses to the single item assessing motivation to make sacrifices provided by a subset of participants during the fourth follow-up assessment $(n=7,951$; completed, on average, 20 days after baseline).

\section{Attitudes Toward Immigrants}

Participants rated their feelings toward "migrants who come to live here" using a 9-point feeling thermometer response scale $\left(0^{\circ}\right.$ : "very cold or unfavorable feeling"; $100^{\circ}$ : "very warm or favorable feeling") (Zavala-Rojas, 2014). Only data from nonimmigrants $(n=56,807)$ were used in analyses involving this variable. To examine change over time, the primary longitudinal analyses used responses provided by a subset of participants during the third follow-up assessment ( $n=5,112$; completed, on average, 21 days following completing of the baseline assessment).

\section{Results}

\section{Analysis Strategy}

Data were analyzed using multilevel models that treated participants as nested within country. Individual-level analyses used group-centered predictors to examine between-person variation within countries (Enders \& Tofighi, 2007). Country-level analyses examined betweencountry effects of country-level predictor variables, which were created by aggregating scores on 
predictor variables across all participants within a country. These predictors are orthogonal to the individual-level predictors, and assess only between-country variation. Concurrent models examined associations between variables measured during the baseline assessment. Indirect effects were tested by constructing 95\% confidence intervals based on 20,000 Monte Carlo simulations (MacKinnon et al., 2004; Preacher \& Selig, 2012).

Longitudinal models examined predictive effects of variables measured at baseline on outcomes measured later in time while controlling for the outcome variable measured at baseline. Although fewer participants volunteered for the longitudinal component relative to the baseline survey, the longitudinal models examine associations between variables over time while ensuring that effects are not spurious due to associations of predictor variables with criterion variables assessed earlier in time. Intercepts were modeled as randomly varying to account for betweencountry differences in criterion variables. Slopes for individual-level predictors were also initially modeled as randomly varying across countries to accommodate any variation across countries in effects of these predictors, although these slopes where subsequently modeled as fixed if their variance parameters were not statistically significant according to Wald tests, or if model convergence depended on modeling slopes as fixed. This was the case for all prospective models. Models were tested using SPSS Version 24, and the default Satterthwaite formula was used to estimate degrees of freedom.

\section{Results of Models Examining Concurrent Associations}

Models testing concurrent associations used data collected at the baseline assessment. Correlation matrices are presented in online supplementary materials. The first set of models examined predictive effects of infection and economic threats on values (see Table 1). At individual and country levels, infection threat was associated with greater prioritization of 
communal values (relative to agentic values), whereas economic threat was associated with reduced prioritization of communal values (relative to agentic values). 


\section{Table 1}

Predictive Effects of Threat on Prioritization of Communal Over Agentic Values

\begin{tabular}{|c|c|c|c|c|}
\hline Predictor & $b$ & $t$ & $p$ & $95 \% \mathrm{CI}$ \\
\hline \multicolumn{5}{|c|}{ Individual-Level Effects } \\
\hline Infection Threat & .09 & 11.15 & $<.001$ & $.08, .11$ \\
\hline Economic Threat & -.08 & -8.65 & $<.001$ & $-.09,-.06$ \\
\hline \multicolumn{5}{|c|}{$\underline{\text { Country-Level Effects }}$} \\
\hline Infection Threat & .47 & 3.83 & $<.001$ & $.23, .72$ \\
\hline Economic Threat & -.31 & -2.43 & .016 & $-.57,-.06$ \\
\hline
\end{tabular}

\section{Prevention Behavior and Social Contact}

Next we tested predictive effects of values on COVID-19 prevention behaviors and social contact while controlling for threats (see Table 2). At both individual and national levels, prioritizing communal values over agentic values predicted greater enactment of COVID-19 prevention behaviors. Infection threat indirectly predicted greater enactment of prevention behaviors through greater prioritization of communal values at the individual level (95\% CI: .01, $.01)$ and at the country level $(95 \% \mathrm{CI}: .06, .29)$, whereas economic threat indirectly predicted reduced enactment of prevention behaviors through a lower prioritization of communal values relative to agency at the individual level $(95 \% \mathrm{CI}:-.01,-.004)$ and country level $(95 \% \mathrm{CI}:-.22,-$ $.02)$.

Models examining each of the individual prevention behaviors produced similar patterns. At the individual level, prioritizing communal values predicted washing hands $(b=.07, t=7.11$, $p<.001,95 \%$ CI: .05, .09), avoiding crowds $(b=.07, t=31, p<.001,95 \% \mathrm{CI}: .06, .09)$, and 
putting oneself in quarantine $(b=.08, t=7.2, p<.001,95 \% \mathrm{CI}: .05, .10)$. Likewise, at the country level, prioritizing communal values predicted washing hands $(b=.22, t=2.88, p=.005$, 95\% CI: .07, .37), avoiding crowds $(b=.40, t=5.52, p<.001,95 \% \mathrm{CI}: .26, .55)$, and putting oneself in quarantine $(b=.37, t=2.17, p=.032,95 \% \mathrm{CI}: .03, .70)$.

Prioritizing communal values also predicted more frequent online social contact at individual and national levels, and reduced in-person social contact at the individual level.

\section{Prosocial Motivation}

Next we examined predictive effects of values on prosocial motivation while controlling for threats (see Table 3). At both levels of analysis, prioritizing communal values over agentic values predicted greater prosocial motivation. Infection threat indirectly predicted greater prosocial motivation through greater prioritization of communal values at the individual level (95\% CI: .01, .02) and at the country level (95\% CI: .13, .52), whereas economic threat indirectly predicted reduced prosocial motivation through a lower prioritization of communal values (relative to agentic values) at the individual level (95\% CI: -.02, -.01) and country level (95\% CI: $-.39,-.04)$

\section{Prejudice}

Next we examined predictive effects of values on attitudes toward immigrants while controlling for threats, using data from nonimmigrant participants (see Table 4). At both individual and national levels, prioritizing communal values over agentic values predicted more positive attitudes toward immigrants. Infection threat indirectly predicted more positive attitudes toward immigrants through greater prioritization of communal values (relative to agentic values) at the individual level (95\% CI: .14, .30) and at the country level (95\% CI: .13, 5.8), whereas economic threat indirectly predicted more negative attitudes toward immigrants through a lower 
prioritization of communal values (relative to agentic values) at individual (95\% CI: -.23, -.11) and country (95\% CI: $-4.49,-.005)$ levels. 


\section{Table 2}

Predictive Effects of Threat and Values on Infection Prevention Behaviors and Social Contact

$\begin{array}{lllll}\text { Predictor } & b & t & p & 95 \% \mathrm{CI}\end{array}$

$\underline{\text { Predicting Infection Prevention Behaviors: Individual-Level Effects }}$

Infection Threat

Economic Threat

Prioritization of Communal Values
.18

.03

.07
$9.26<.001 \quad .14, .22$

2.66

.011

$.01, .05$

$9.70<.001$

$.06, .09$

\begin{tabular}{|c|c|c|c|c|}
\hline \multicolumn{5}{|c|}{ Predicting Infection Prevention Behaviors: Country-Level Effects } \\
\hline Infection Threat & -.03 & -.23 & .823 & $-.27, .21$ \\
\hline Economic Threat & .22 & 1.84 & .067 & $-.02, .47$ \\
\hline Prioritization of Communal Values & .33 & 3.67 & .001 & $.15, .50$ \\
\hline \multicolumn{5}{|c|}{ Predicting In-Person Social Contact: Individual-Level Effects } \\
\hline Infection Threat & -.13 & -5.15 & $<.001$ & $-.18,-.08$ \\
\hline Economic Threat & -.02 & -.97 & .339 & $-.08, .03$ \\
\hline Prioritization of Communal Values & -.03 & -2.47 & .014 & $-.04,-.01$ \\
\hline \multicolumn{5}{|c|}{ Predicting In-Person Social Contact: Country-Level Effects } \\
\hline Infection Threat & -1.05 & -2.74 & .007 & $-1.81,-.29$ \\
\hline Economic Threat & .80 & 2.14 & .034 & $-.06,1.54$ \\
\hline Prioritization of Communal Values & .18 & .64 & .526 & $-.37, .73$ \\
\hline \multicolumn{5}{|c|}{$\underline{\text { Predicting Online Social Contact: Individual-Level Effects }}$} \\
\hline Infection Threat & .20 & 7.64 & $<.001$ & $.15, .25$ \\
\hline Economic Threat & -.05 & -3.81 & $<.001$ & $-.08,-.03$ \\
\hline Prioritization of Communal Values & .13 & 12.28 & $<.001$ & $.11, .15$ \\
\hline
\end{tabular}




\begin{tabular}{lcccc}
\hline \multicolumn{5}{c}{ Predicting Online Social Contact: Country-Level Effects } \\
Infection Threat & .08 & .236 & .814 & $-.57, .73$ \\
Economic Threat & -.09 & -.28 & .783 & $-.74, .57$ \\
Prioritization of Communal Values & .83 & 3.42 & .001 & $.35,1.31$ \\
\hline
\end{tabular}




\section{Table 3}

Predictive Effects of Threat and Values on Prosocial Motivation

\begin{tabular}{|c|c|c|c|c|}
\hline Predictor & $b$ & $t$ & $p$ & $95 \% \mathrm{CI}$ \\
\hline \multicolumn{5}{|c|}{$\underline{\text { Individual-Level Effects }}$} \\
\hline Infection Threat & .08 & 5.13 & $<.001$ & $.05, .12$ \\
\hline Economic Threat & -.14 & -8.49 & $<.001$ & $-.18,-.11$ \\
\hline Prioritization of Communal Values & .23 & 50.92 & $<.001$ & $.20, .25$ \\
\hline \multicolumn{5}{|c|}{$\underline{\text { Country-Level Effects }}$} \\
\hline Infection Threat & .09 & .50 & .615 & $-.25, .42$ \\
\hline Economic Threat & -.03 & -.21 & .838 & $-.37, .30$ \\
\hline Prioritization of Communal Values & .63 & 5.06 & $<.001$ & $.38, .88$ \\
\hline
\end{tabular}




\section{Table 4}

Predictive Effects of Threat and Values on Attitudes Toward Immigrants

\begin{tabular}{|c|c|c|c|c|}
\hline Predictor & $b$ & $t$ & $p$ & $95 \% \mathrm{CI}$ \\
\hline \multicolumn{5}{|c|}{ Individual-Level Effects } \\
\hline Infection Threat & .41 & 1.65 & .108 & $-.09, .92$ \\
\hline Economic Threat & -2.33 & -7.25 & $<.001$ & $-2.98,-1.68$ \\
\hline Prioritization of Communal Values & 2.39 & 6.57 & $<.001$ & $1.66,3.11$ \\
\hline \multicolumn{5}{|c|}{$\underline{\text { Country-Level Effects }}$} \\
\hline Infection Threat & 10.83 & 2.95 & .004 & $3.56,18.09$ \\
\hline Economic Threat & -13.64 & -3.76 & $<.001$ & $-20.82,-6.47$ \\
\hline Prioritization of Communal Values & 5.74 & 2.10 & .037 & $.34,11.13$ \\
\hline
\end{tabular}

Robustness analyses. As indicated in the online supplementary materials, sample size varied considerably across countries. Several countries were represented by only a few participants, and it is not clear whether the aggregates of responses by these participants serve as reliable indicators of their country-level variables. We conducted additional analyses examining the between-country effects described above after restricting the sample to the 42 countries represented by at least 100 participants. Results of these analyses, presented in supplementary materials, indicate that all country-level effects of values remained significant with the exception of the effect on attitudes toward immigrants. These analyses are considerably more conservative given that there are based on a much smaller sample of countries. Furthermore, additional analyses controlling for participants gender, at the individual and national level, demonstrated 
that the effects of threats on values, and the effects of values on the outcomes, were not explained by associations of predictor variables with gender. ${ }^{2}$ 


\section{Results of Models Examining Change Over Time}

We conducted additional analyses to examine predictive effects of variables assessed during the baseline assessment on criterion variables measured later in time. The baseline assessment of the criterion variable was included as a covariate, which ensures that the effects of key predictors on subsequent criterion variables are not explained by contemporaneous associations between these variables. Below we describe the effects associated with the key predictor variables. Effects of all control variables are presented in supplementary materials.

Infection threat and economic threat measured at baseline were modeled as predictors of values assessed in the sixth follow-up survey. At the individual level, baseline infection threat predicted greater subsequent prioritization of communal values (relative to agentic values), $b=$ $.04, t=2.57, p=.014,95 \% \mathrm{CI}(.01, .07)$. In contrast, baseline economic threat did not significantly predict later values, but the effect was in the opposite direction, similar to the crosssectional findings, $b=-.02, t=-1.48, p=.154,95 \% \mathrm{CI}(-.05, .01)$.

Baseline values was modeled as a predictor of infection prevention behaviors (measured in follow-up wave 4), prosocial motivation (measured in wave 4), and attitudes toward immigrants (measured in wave 3) while controlling for threats and the criterion variable assessed at baseline. At the individual level, those who more strongly prioritized communal values at baseline subsequently engaged in more prevention behaviors, $b=.03, t=3.27, p=.001,95 \%$ $\mathrm{CI}(.01, .05)$; adopted greater prosocial motivation, $b=.10, t=6.42, p<.001,95 \% \mathrm{CI}(.07, .13)$; and harbored more positive attitudes toward immigrants, $b=.69, t=3.15, p=.002,95 \% \mathrm{CI}(.26$, 1.12) in the follow-up assessment. 
Analogous prospective effects at the country level were not significant, perhaps because of the lower sample size (i.e., few participants per country) and, thus, reduced precision in estimating country-level means in these longitudinal analyses.

Robustness analyses. Additional analyses examined the robustness of the longitudinal findings. These analyses indicate that the key longitudinal effects did not depend on the amount of time that elapsed between baseline and follow-up assessments, and were consistent when using criterion variables measured during other assessment waves (see supplementary materials).

\section{Discussion}

The current research suggests that people's experiences of COVID-19 as a threat to health versus economics are associated with diverging values, which predict important responses to the pandemic. The threat of getting infected was associated with prioritization of communal values focusing on caring for others' welfare and maintaining harmonious relationships, both concurrently and over time. This effect is consistent with research suggesting that people respond to threats to their physical health and reminders of their mortality with affiliation motivation (Mikulincer et al., 2003; Schachter, 1959), and it may suggest the operation of an adaptive mechanism to seek protection and support from others when confronted with physical danger (Baumeister \& Leary, 1995) and environmental pathogens (Thornhill \& Fincher, 2014).

Experiencing COVID-19 as an economic threat instead predicted prioritization of agentic values emphasizing individual achievement and advancement, relative to communal values. This finding may suggest that most people perceive agency to be more promising than communion for dispelling economic threats, and is consistent with prior research suggesting that economic hardship predicts reduced commitment to maintaining relationships (Barton et al., 2015) and reduced relationship quality (Barton et al., 2015; Conger et al., 1999; Vinokur et al., 1996). It is 
also consistent with research suggesting that thinking about money reduces affiliation motivation and motivates pursuit of solitary activities (Hagemeyer et al., 2015; Kumashiro et al., 2008; Lodder et al., 2019; Vohs, 2015). Although this prioritization of agency over communion may often be useful for improving one's financial well-being (Shim et al., 2009) and fostering economic growth (Granato et al., 1996), our data suggest that it may also have costs.

Those who prioritized communion relative to agency were more likely to report engaging in prevention behaviors (e.g., washing hands, avoiding crowded places, avoiding close contact with others), both concurrently and over time. We expect that most people are aware of the benefits of these behaviors for other people and society at large, leading communal-focused people to enact them, in part, as means to protect others' welfare. These communal inclinations may also induce a desire for social contact, which could endanger health in the context of a pandemic. Thus, care for one's own and others' welfare may conflict with the desire for social contact for those who value communion. Our results suggest that communal-focused people resolve this dilemma by engaging in less frequent in-person social contact, yet more frequent online contact. This behavioral pattern may reflect efforts to satisfy multiple goals, including protecting health and connecting with others. Whereas online social contact may satisfy both goals, in-person social contact may satisfy connection goals at the expense of protection goals, prompting communal-focused individuals to use online contact as a substitute means of satisfying their goals to connect with others during the pandemic.

People who prioritized communal values were more willing to help those suffering from COVID-19, both concurrently and over time. This finding is important because providing help can mitigate the psychological, physical, and economic burdens of COVID-19. For instance, people who perceived their social network members as supportive were less anxious, irritable, 
and depressed during the COVID-19 pandemic, and they reported better sleep quality (Grey et al., 2020). Social network members' prioritization of communal values in response to COVID-19 infection threats may have eased the mental health burden of the pandemic through their tendencies to provide greater support to others. The implications of values for the mental health of social network members during disease outbreaks should be examined in future research.

People who prioritized communal values also reported more positive attitudes toward immigrants, both concurrently and over time. Disease and economic threats tend to be associated with greater prejudice (Butz \& Yogeeswaran, 2011; Schaller \& Neuberg, 2012), and immigrants are particularly vulnerable to being seen as carrying foreign diseases, undermining culture, and consuming scare resources (Schaller \& Neuberg, 2012; Stephan et al., 1999). Hence, COVID-19 has the capacity to exacerbate tensions, particularly between nationals and immigrants. The current research suggests that the impact of disease outbreaks on heightened prejudice may depend on the values activated by the threats imposed by these outbreaks. Disease threats that activate communal values may not exacerbate prejudice. Similarly, earlier research suggested that individual and state-level collectivism attenuated the link between perceived vulnerability to the Ebola virus and xenophobia (Kim et al., 2016). The current research builds on these findings by revealing distinct pathways through which disease outbreaks may ameliorate or exacerbate prejudice, one involving infection threat and a prioritization of communion, and the other involving economic threat and a prioritization of agency.

These findings contribute to the limited literature on predictors of individual value change. Value change is thought to be a result of both automatic and effortful adaptation to lifealtering events and environmental changes (Bardi \& Goodwin, 2011; Bardi et al., 2009). The current research demonstrated that concerns about being infected with COVID-19 predicted 
individual-level change over time in prioritizing communal values relative to agentic values. These results provide novel longitudinal and individual-level evidence supporting arguments that pathogen threats motivate people to emphasize affiliation and deemphasize exploration (e.g., Chiao \& Blizinsky, 2009; Thornhill \& Fincher, 2014). Furthermore, communal values were associated with greater infection prevention behavior and prosocial motivation concurrently and over time, suggesting that this shift toward communion in response to pathogen threats may facilitate individual and collective adaptation, consistent with arguments that value change often promotes adaptation to environmental challenges (Bardi \& Goodwin, 2011; Bardi et al., 2009) and, more specifically, that elevated collectivism in response to pathogen threats protects individuals and groups (e.g., Chiao \& Blizinsky, 2009; Thornhill \& Fincher, 2014). The current research further contributes to this literature by underscoring the role of subjective construal. The same life-changing event may be experienced differently across individuals and cultures, such as by construing the event as a threat to health versus economics, and these subjective meanings, in turn, may elicit different trajectories of value change. The current results also contribute to the growing literature on psychological responses to pandemics and COVID-19 in particular (Van Bavel et al., 2020) by pointing to the role of value adaptation in guiding a variety of responses to the COVID-19 pandemic.

The cross-sectional, country-level analyses replicated the individual-level findings. Countries that perceived greater infection threats tended to prioritize communion, whereas countries that perceived greater economic threats tended to prioritize agency. In turn, countries that valued communion over agency had residents who engaged in more prevention behaviors, were more willing to help others with the pandemic, and held more positive attitudes toward immigrants. These findings suggest the relevance of cultural differences in communal and 
agentic values for explaining how nations respond to health and economic disease threats. Prior research supporting the behavioral immune system and parasite stress theory of sociality suggests that regional differences in the prevalence of disease predicts cross-cultural variability in cognitions, behaviors, and psychological characteristics that are relevant to the mitigation of risk (Fincher et al., 2008; Schaller, 2006; Thornhill \& Fincher, 2014). Building on this perspective, the current research suggests that the particular type of threat imposed by the prevalence of disease, as well as the values activated by the threat, play a role in shaping other psychological and behavioral responses to disease prevalence at the national level. Consistent with these theoretical frameworks, the current research suggests that concerns about infection are associated with greater prioritization of communal values at the national level. Furthermore, given that this prioritization was associated with national-level infection prevention and prosocial behavior, the tendency to respond to national-level infection concerns with communal values appeared to facilitate collective protection from pathogen threats. However, when the COVID-19 pandemic was instead experienced as primarily as an economic threat, nations prioritized agency over communion. Given that agentic values are associated with individual and collective financial wellbeing (Granato et al., 1996; Shim et al., 2009), an agentic national response may indeed be useful for responding to perceived economic threats, although it would seem to also have costs (i.e., reduced infection prevention behaviors and prosocial motivation, more antipathy toward immigrants). Thus, one of the broadest theoretical contributions of the current research is that COVID-19 specifically, and perhaps pandemics more generally, can be viewed as threatening to different aspects of human welfare, and the way it is construed will have implications for how values will adapt, as well as downstream consequences of this 
adaption of values. The adaptation of values appears to be functionally tuned to the dominant threat posed by the COVID-19 pandemic.

It is important to acknowledge some limitations of the current research. We were not able to obtain a representative sample in every country, and the findings may not generalize to all people. Furthermore, it is unclear whether these findings generalize to other events that threaten people's health and economic welfare. Although most of our findings are consistent with our theoretical perspective, we did not manipulate threat or values, and this research should not be interpreted as suggesting causal effects. We did not include wearing face masks in our index of prevention behaviors because, at the time this study was launched, wearing masks was not a recommended strategy for the general public by the World Health Organization. Finally, given the large-scale nature of the current project, abbreviated versions of measures were administered.

The current research suggests the usefulness of value change interventions for improving people's responses to pandemics. Interventions using evocative images to increase care for humanity have effectively changed values in prior research (Reese et al., 2015), as have interventions that create dissonance by demonstrating that one's values are similar to negative role models, or different from positive role models (Grube et al., 1994; Rokeach, 1968). Given the associations between prioritizing communion, infection prevention behaviors, and prosocial behavior, perhaps interventions that encourage people to adopt communal values and derive pride and a sense of significance from communal pursuits would help reduce disease prevalence and burdens. These interventions may be particularly important for those who emphasize agency due to economic threats. However, given that sustained prioritization of communion may be difficult for those experiencing economic threats, the benefits of these interventions may depend on the existence of social welfare systems that provide economic security during disease 
outbreaks. Given their potentially devastating consequences, economic threats may compel agency for those without an economic safeguard.

Taken together, these findings suggest an important role of values in shaping responses to COVID-19, and perhaps responses to other outbreaks and disasters. The results suggest that whether disease outbreaks elicit prevention behaviors that control the pandemic, prosocial responses that help people cope, and intergroup harmony depends on the type of threat and the values it elicits. By virtue of eliciting a communal response, threats to health appear to facilitate these outcomes, and bring people together. Due to evoking a prioritization of agency over communion, economic threats may instead undermine prevention and helping, and drive people apart. 


\section{References}

Ackerman, J. M., Hill, S. E., \& Murray, D. R. (2018). The behavioral immune system: Current concerns and future directions. Social and Personality Psychology Compass, 12(2), e12371.

Barua, S. (2020). Understanding coronanomics: The economic implications of the coronavirus (COVID-19) pandemic. SSRN Electronic Journal.

Bardi, A., \& Goodwin, R. (2011). The dual route to value change: Individual processes and cultural moderators. Journal of Cross-Cultural Psychology, 42(2), 271-287.

Bardi, A., Lee, J. A., Hofmann-Towfigh, N., \& Soutar, G. (2009). The structure of intraindividual value change. Journal of Personality and Social Psychology, 97, 913-929.

Barton, A. W., Futris, T. G., \& Nielsen, R. B. (2015). Linking financial distress to marital quality: The intermediary roles of demand/withdraw and spousal gratitude expressions. Personal Relationships, 22(3), 536-549.

Baumeister, R. F., \& Leary, M. R. (1995). The need to belong: Desire for interpersonal attachments as a fundamental human motivation. Psychological Bulletin, 117(3), 497-529.

Butz, D. A., \& Yogeeswaran, K. (2011). A new threat in the air: Macroeconomic threat increases prejudice against Asian Americans. Journal of Experimental Social Psychology, 47(1), 2227.

Chiao, J. Y., \& Blizinsky, K. D. (2010). Culture-gene coevolution of individualism-collectivism and the serotonin transporter gene. Proceedings of the Royal Society B: Biological Sciences, 277(1681), 529-537.

Conger, R. D., Rueter, M. A., \& Elder Jr, G. H. (1999). Couple resilience to economic pressure. Journal of Personality and Social Psychology, 76(1), 54-71. 
Daniel, E., Bilgin, A. S., Brezina, I., Strohmeier, C. E., \& Vainre, M. (2015). Values and helping behavior: A study in four cultures. International Journal of Psychology, 50(3), 186-192.

Deters, F. G., \& Mehl, M. R. (2013). Does posting Facebook status updates increase or decrease loneliness? An online social networking experiment. Social Psychological and Ppersonality Science, 4(5), 579-586.

Dowd, J. B., Andriano, L., Brazel, D. M., Rotondi, V., Block, P., Ding, X., Liu, Y., Mills, M. C. (2020). Demographic science aids in understanding the spread and fatality rates of COVID19. Proceedings of the National Academy of Sciences, 117(18), 9696-9698.

Dryhurst, S., Schneider, C. R., Kerr, J., Freeman, A. L., Recchia, G., Van Der Bles, A. M., Spiegelhalter, D., \& van der Linden, S. (2020). Risk perceptions of COVID-19 around the world. Journal of Risk Research, 1-13.

Enders, C. K., \& Tofighi, D. (2007). Centering predictor variables in cross-sectional multilevel models: A new look at an old issue. Psychological Methods, 12(2), 121-138.

Fincher, C. L., \& Thornhill, R. (2012). Parasite-stress promotes in-group assortative sociality: The cases of strong family ties and heightened religiosity. Behavioral and Brain Sciences, 35(2), $61-79$

Fincher, C. L., Thornhill, R., Murray, D. R., \& Schaller, M. (2008). Pathogen prevalence predicts human cross-cultural variability in individualism/collectivism. Proceedings of the Royal Society B: Biological Sciences, 275(1640), 1279-1285.

Fischer, R., \& Boer, D. (2016). Values: the dynamic nexus between biology, ecology and culture. Current Opinion in Psychology, 8, 155-160.

Goodell, J. W. (2020). COVID-19 and finance: Agendas for future research. Finance Research Letters, 101512. 
Granato, J., Inglehart, R., \& Leblang, D. (1996). The effect of cultural values on economic development: Theory, hypotheses, and some empirical tests. American Journal of Political Science, 40, 607-631.

Grey, I., Arora, T., Thomas, J., Saneh, A., Tohme, P., \& Abi-Habib, R. (2020). The role of perceived social support on depression and sleep during the COVID-19 pandemic. Psychiatry Research, 293, 113452.

Grube, J. W., Mayton, D. M., \& Ball-Rokeach, S. J. (1994). Inducing change in values, attitudes, and behaviors: Belief system theory and the method of value self-confrontation. Journal of Social Issues, 50(4), 153-173.

Hagemeyer, B., Schönbrodt, F. D., Neyer, F. J., Neberich, W., \& Asendorpf, J. B. (2015). When "together" means "too close": Agency motives and relationship functioning in coresident and living-apart-together couples. Journal of Personality and Social Psychology, 109, 813-835.

\section{https://doi.org/10.1037/pspi0000031}

Hartman, T. K., Stocks, T. V., McKay, R., Gibson-Miller, J., Levita, L., Martinez, A. P., ... \& Bentall, R. P. (2020). The authoritarian dynamic during the COVID-19 pandemic: Effects on nationalism and anti-immigrant sentiment. Social Psychological and Personality Science, 1948550620978023.

Holmes, E. A., O'Connor, R. C., Perry, V. H., Tracey, I., Wessely, S., Arseneault, L., Ballard, C., Christensen, H., Silver, R. C., Everall, I., Ford, T., John, A., Kabir, T., King, K., Madan, I., Michie, S., Przybylski, A. K., Shafran, R., Sweeney, A., Worthman, C. M., Yardley, L., Cowan, K., Cope, C., Hotopf, M., \& Bullmore, E. (2020). Multidisciplinary research priorities for the COVID-19 pandemic: a call for action for mental health science. The Lancet Psychiatry, 547-560. 
Islam, N., Sharp, S. J., Chowell, G., Shabnam, S., Kawachi, I., Lacey, B., Massaro, J. M., D’Agostino, R. B., \& White, M. (2020). Physical distancing interventions and incidence of coronavirus disease 2019: natural experiment in 149 countries. The BMJ, 370.

Kahle, L. R., Beatty, S. E., \& Homer, P. (1986). Alternative measurement approaches to consumer values: the list of values (LOV) and values and life style (VALS). Journal of Consumer Research, 13(3), 405-409.

Kaniasty, K., \& Norris, F. H. (1993). A test of the social support deterioration model in the context of natural disaster. Journal of Personality and Social Psychology, 64(3), 395-408.

Kim, H. S., Sherman, D. K., \& Updegraff, J. A. (2016). Fear of Ebola: The influence of collectivism on xenophobic threat responses. Psychological Science, 27(7), 935-944.

Kruglanski, A. W., Shah, J. Y., Fishbach, A., Friedman, R., Chun, W. Y., \& Sleeth-Keppler, D. (2002). A theory of goal systems. Advances in Experimental Social Psychology, 34, 331-378.

Kumashiro, M., Rusbult, C. E., \& Finkel, E. J. (2008). Navigating personal and relational concerns: The quest for equilibrium. Journal of Personality and Social Psychology, 95(1), 94-110.

Leander, N. P., Agostini, M., Stroebe, W., Kreienkamp, J., Spears, R., Kuppens, T., Van Zomeren, M., Otten, S., \& Kruglanski, A. (2019). Frustration-affirmation? Thwarted goals motivate compliance with social norms for violence and nonviolence. Journal of Personality and Social Psychology, 119, 249-71.

Leong, C.-H., \& Ward, C. (2006). Cultural values and attitudes toward immigrants and multiculturalism: The case of the Eurobarometer survey on racism and xenophobia. International Journal of Intercultural Relations, 30(6), 799-810. 
Locke, K. D. (2000). Circumplex scales of interpersonal values: Reliability, validity, and applicability to interpersonal problems and personality disorders. Journal of Personality Assessment, 75(2), 249-267.

Lodder, P., Ong, H. H., Grasman, R. P., \& Wicherts, J. M. (2019). A comprehensive meta-analysis of money priming. Journal of Experimental Psychology: General, 148(4), 688-712.

MacKinnon, D. P., Lockwood, C. M., \& Williams, J. (2004). Confidence limits for the indirect effect: Distribution of the product and resampling methods. Multivariate Behavioral Research, 39(1), 99-128.

McGuire, A. P., Gauthier, J. M., Anderson, L. M., Hollingsworth, D. W., Tracy, M., Galea, S., \& Coffey, S. F. (2018). Social support moderates effects of natural disaster exposure on depression and posttraumatic stress disorder symptoms: Effects for displaced and nondisplaced residents. Journal of Traumatic Stress, 31, 223-233.

Mikulincer, M., Florian, V., \& Hirschberger, G. (2003). The existential function of close relationships: Introducing death into the science of love. Personality and Social Psychology Review, 7(1), 20-40.

Mikulincer, M., \& Shaver, P. R. (2009). An attachment and behavioral systems perspective on social support. Journal of Social and Personal Relationships, 26(1), 7-19.

Murray, D. R., \& Schaller, M. (2016). The behavioral immune system: Implications for social cognition, social interaction, and social influence. Advances in Experimental Social Psychology, 53, 75-129.

Murray, D. R., Trudeau, R., \& Schaller, M. (2011). On the origins of cultural differences in conformity: Four tests of the pathogen prevalence hypothesis. Personality and Social Psychology Bulletin, 37(3), 318-329. 
Nicola, M., Alsafi, Z., Sohrabi, C., Kerwan, A., Al-Jabir, A., Iosifidis, C., Agha, M., \& Agha, R. (2020). The socio-economic implications of the coronavirus and COVID-19 pandemic: a review. International Journal of Surgery, 78, 185-193.

Preacher, K. J., \& Selig, J. P. (2012). Advantages of Monte Carlo confidence intervals for indirect effects. Communication Methods and Measures, 6(2), 77-98.

Prem, K., Liu, Y., Russell, T. W., Kucharski, A. J., Eggo, R. M., Davies, N., Centre for the Mathematical Modelling of Infectious Diseases COVID-19 Working Group, Jit, M., \& Klepac, P. (2020). The effect of control strategies to reduce social mixing on outcomes of the COVID-19 epidemic in Wuhan, China: a modelling study. The Lancet Public Health, 5, E261-E270.

Reese, G., Proch, J., \& Finn, C. (2015). Identification with all humanity: The role of self-definition and self-investment. European Journal of Social Psychology, 45(4), 426-440.

Roberto, K. J., Johnson, A. F., \& Rauhaus, B. M. (2020). Stigmatization and prejudice during the COVID-19 pandemic. Administrative Theory \& Praxis, 42, 364-378.

Rokeach, M. (1968). The role of values in public opinion research. Public Opinion Quarterly, 32(4), 547-559. doi:10.1086/267645

Rokeach, M. (1973). The Nature of Human Values. New York: The Free Press.

Rokeach, M., \& Ball-Rokeach, S. J. (1989). Stability and change in American value priorities, 19681981. American Psychologist, 44(5), 775-784. https://doi.org/10.1037/0003-066X.44.5.775

Sagiv, L., Roccas, S., Cieciuch, J., \& Schwartz, S. H. (2017). Personal values in human life. Nature Human Behaviour, 1(9), 630-639. 
Shim, S., Xiao, J. J., Barber, B. L., \& Lyons, A. C. (2009). Pathways to life success: A conceptual model of financial well-being for young adults. Journal of Applied Developmental Psychology, 30(6), 708-723.

Shin, H., \& Dovidio, J. F. (2018). Differences, threats, values, and country-specific prejudice toward immigrants and foreign workers in three major receiving countries: The United States, Germany, and Australia. Journal of Social Issues, 74(4), 737-755.

Saroglou, V., Lamkaddem, B., Van Pachterbeke, M., \& Buxant, C. (2009). Host society's dislike of the Islamic veil: The role of subtle prejudice, values, and religion. International Journal of Intercultural Relations, 33(5), 419-428.

Schachter, S. (1959). The psychology of affiliation: Stanford University Press.

Schaller, M. (2006). Parasites, behavioral defenses, and thesocial psychological mechanisms through which cul-tures are evoked. Psychological Inquiry, 17, 96-101.

Schaller, M., \& Neuberg, S. L. (2012). Danger, disease, and the nature of prejudice (s). In Advances in Experimental Social Psychology (Vol. 46, pp. 1-54): Elsevier.

Schwartz, S. H. (2007). Value orientations: Measurement, antecedents and consequences across nations. In R. Jowell, C. Roberts, R. FitzGerald, \& G. Eva (Eds.), Measuring attitudes crossnationally: Lessons from the European Social Survey (pp. 161-193). London: Sage.

Schwartz, S. H. (2015). Basic individual values: Sources and consequences. In D. Sander \& T. Brosch (Eds.), Handbook of value: Perspectives from economics, neuroscience, philosophy, psychology and sociology (pp. 63-84). Oxford: UK: Oxford University Press.

Schwartz, S. H., \& Sagiv, L. (1995). Identifying culture-specifics in the content and structure of values. Journal of Cross-Cultural Psychology, 26(1), 92-116. 
Selenko, E. \& Batinic B. (2011). Beyond debt. A moderator analysis of the relationship between perceived financial strain and mental health. Social Science and Medicine, 73, 1725-1732.

Sherman, D. K., \& Cohen, G. L. (2006). The psychology of self-defense: Self-affirmation theory. Advances in Experimental Social Psychology, 38, 183-242.

Smith, E. B., Menon, T., \& Thompson, L. (2012). Status differences in thecognitive activation of social networks. Organization Science, 23, 67-82. http://dx.doi.org/10.1287/orsc.1100.0643

Stephan, W. G., Ybarra, O., \& Bachman, G. (1999). Prejudice toward immigrants. Journal of Applied Social Psychology, 29(11), 2221-2237.

Strümpfer, D. J. W. (1970). Fear and affiliation during a disaster. The Journal of Social Psychology, $82(2), 263-268$.

Sturgeon, J. A., Zautra, A. J., \& Okun, M. A. (2014). Associations between financial stress and interpersonal events: A daily diary study of middle-aged adults and their life circumstances. Psychology and Aging, 29(4), 803-813.

Teater, B., Chonody, J. M., \& Hannan, K. (2021). Meeting social needs and loneliness in a time of social distancing under COVID-19: A comparison among young, middle, and older adults. Journal of Human Behavior in the Social Environment, 31, 43-59.

Thornhill, R., \& Fincher, C. L. (2014). The parasite-stress theory of sociality, the behavioral immune system, and human social and cognitive uniqueness. Evolutionary Behavioral Sciences, 8(4), 257-264. https://doi.org/10.1037/ebs0000020

Thornhill, R., \& Fincher, C. L. (2014). Collectivism-individualism, family ties, and philopatry. In R. Thornhill \& C. L. Fincher, The Parasite-Stress Theory of Values and Sociality: Infectious Disease, Hisotry and Human Values Worldwide (pp. 113-170). Cham (Switzerland) and New York: Springer. 
Trapnell, P. D., \& Paulhus, D. L. (2012). Agentic and communal values: Their scope and measurement. Journal of Personality Assessment, 94(1), 39-52.

Tsai, H. H., Tsai, Y. F., Wang, H. H., Chang, Y. C., \& Chu, H. H. (2010). Videoconference program enhances social support, loneliness, and depressive status of elderly nursing home residents. Aging and Mental Health, 14(8), 947-954.

Van Zomeren, M., Postmes, T., \& Spears, R. (2008). Toward an integrative social identity model of collective action: A quantitative research synthesis of three socio-psychological perspectives. Psychological Bulletin, 134(4), 504-535.

Vander Elst, T., De Witte, H., \& De Cuyper, N. 2014. The Job Insecurity Scale: A psychometric evaluation across five European countries. European Journal of Work and Organizational Psychology, 23, 364-380.

Vinokur, A. D., Price, R. H., \& Caplan, R. D. (1996). Hard times and hurtful partners: How financial strain affects depression and relationship satisfaction of unemployed persons and their spouses. Journal of Personality and Social Psychology, 71(1), 166-179.

Vohs, K. D. (2015). Money priming can change people's thoughts, feelings, motivations, and behaviors: An update on 10 years of experiments. Journal of Experimental Psychology: General, 144(4), e86.

Williamson, H. C., Karney, B. R., \& Bradbury, T. N. (2013). Financial strain and stressful events predict newlyweds' negative communication independent of relationship satisfaction. Journal of Family Psychology, 27(1), 65-75.

World Health Organization. Advice on the use of masks in the context of COVID-19: Interim guidance. https://www.who.int/publications/i/item/advice-on-the-use-of-masks-in-the- 
community-during-home-care-and-in-healthcare-settings-in-the-context-of-the-novelcoronavirus-(2019-ncov)-outbreak (2020).

World Health Organization. (2021, January). Coronavirus disease (COVID-19) Weekly Epidemiological Update and Weekly Operational Update. https://www.who.int/emergencies/diseases/novel-coronavirus-2019/situation-reports.

Wu, B. P., \& Chang, L. (2012). The social impact of pathogen threat: How disease salience influences conformity. Personality and Individual Differences, 53(1), 50-54.

Zavala-Rojas, D. (2014). Thermometer scale (feeling thermometer). In A. C. Michalos (ed), Encyclopedia of Quality of Life and Well-Being Research. Springer, Dordrecht. https://doi.org/10.1007/978-94-007-0753-5 1028 


\section{Footnotes}

${ }^{1}$ Sample size per country is provided in online supplementary materials. Given our interest in testing our model at the global level, we included all participants in our primary analyses, regardless of country sample size.

${ }^{2}$ We tested additional models to examine whether the individual-level effects of values were moderated by country-level values. Specifically, we retested each of the individual-level models after including country-level values and a product term representing the interaction between individual-level values and country-level values as additional predictors. The models controlled for country-level infection threat, country-level economic threat, and product terms representing the cross-level interactions between individual-level and country-level threats. Country-level values did not moderate the effect of individual-level values on containment behavior $(p=.21)$, in-person social contact $(p=.07)$, online social contact $(p=.50)$, prosocial motivation $(p=.84)$, or attitudes toward immigrants $(p=.72)$. Thus, individual-level and country-level effects of values appeared to be independent. 